\title{
The Uniqueness of Adjacent Beaches for Tsunami Mitigation Ef- forts - A Case Study from Phuket, Thailand
}

\author{
R. Zobel ${ }^{1}$, H. Dürrast ${ }^{2}$. P. Tandayya ${ }^{3}$ \\ 1 Prince of Songkla University, Hat Yai, Thailand, r.zobel@ntlworld.com \\ 2 Prince of Songkla University, Hat Yai, Thailand, helmut.j@psu.ac.th
}

3 Prince of Songkla University, Hat Yai, Thailand, pichaya@coe.psu.ac.th

In the aftermath of the 26 December 2004 Indian Ocean Tsunami, it was observed, that the waves had different impact at three different beaches in Phuket, Thailand, the „Pearl of the Andaman“ The best known and most popular is Patong Beach, where many tourists and local people died or were injured. It is a wide curve beach, with a shallow sea, suitable for safe swimming, because it is only gently shelving. The smaller Kamala beach, north of Patong, is similar in this respect. Both suffered severely from the tsunami. However, Surin Beach shelves steeply in a series of steps, from a shelving beach, reached from a small car park and restaurant, itself about a meter above the sand. Relatively little damage was done here.

These details show that each beach is unique and must be considered separately, even at relatively short geographical distances, like in Phuket. This uniqueness has direct implications for run-up modelling and simulation, for tsunami mitigation efforts and consequently for insurance purposes; especially for Phuket, and for Phang Nga further north, where many hotels and resorts are located close to the beaches. Similar situation can be found in countries around the Indian Ocean.

Current work, reported here, concerns evaluation of some specific beaches in Phuket in respect of the size, shape, orientation and shelving, gradients and features of surface and local seabed. Of particular interest are the horns of these beaches and of the very different consequences for each of the selected beaches in respect of the December 2004 tsunami.

The principle beaches concerned are Patong Beach, Kamala Beach, and Surin Beach. These beaches were all affected in different ways, especially in respect of the seriousness of the consequences for people and property. Nai Yang Beach, close to the airport was also considered, along with Rawai beach on the Eastern side of the island, which received the reflected wave from Krabi.

Observations from local Thai people have provided useful information. Recently, sand samples have been taken from these beaches to ascertain their characteristics of density, roughness and particle size and distribution for modelling purposes. Observations of slope and shelving of beaches and of the horns of ends of the beaches have been made to ascertain their susceptibility to approaching tsunami.

Bousinesq and RANS approaches and their relevance to the proposed studies are considered, using a larger number of parallel PCs for simulation studies. Of particular interest are cfd model considerations for various aspects of pickup, carriage, and deposit of sand at high Reynolds numbers and the effects of such sand transport on consequences for beach damage and inundation. The basis of the equations and approximations will be initially obtained from previous work and sources. In respect of this, use of existing estuarine approaches of silt carriage and deposit are being evaluated.

We propose the use of existing simulation results at high Reynolds numbers for initial validation, and are also considering the use of local flume and wave basin facilities for experimental model validation, although it is recognised that scaling may not be appropriate at such high Reynolds numbers.

Consideration of the use of these models and simulations in respect to DEWS warnings and mitigation efforts of likely effects on specific beaches on the West Coast of Thailand are the principle aims of this work.

\section{Literature}

Zobel, R., Durrast, H. \& Tandayya, P. (2006) Modelling and Simulation of the Impact of Tsunami Waves at Beaches and Coastlines for Disaster Reduction in Thailand. Invited paper in Int. J. of Simulation, Vol. 7, No 4-5. UKSim, Nottingham. pp. 40-50. 